\title{
A Study On Online Language Learning Environment For College Students In Tamil Nadu
}

\section{J. Jeyarania ${ }^{\mathrm{a}}$ Dr.R. Vasanthan ${ }^{\mathrm{b} *}$}

\author{
${ }^{a}$ Research Scholar, Department of English, National College (Autonomous), (Affiliated to Bharathidasan \\ University), Tiruchirappalli. \\ b*Associate Professor and Head, Department of English (UAP), National College (Autonomous), (Affiliated to \\ Bharathidasan University), Tiruchirappalli. E-mail: vasanthan@nct.ac.in
}

\section{Article History: Received: 11 January 2021; Accepted: 27 February 2021; Published online: 5 April 2021}

\begin{abstract}
Online learning environment and strategies provide ample and valid opportunities to explore, discover and perform with the wonders of technology. This paper surveys and analyses the online language learning environment of college students in Tamil Nadu. The study examines the specific advantages of the learning environment and the instructional methods employed in the virtual learning environment. The study is undertaken with college students from different districts of Tamil Nadu who underwent a pre-assessment and a post assessment before and after they participated in the structured online English language classes constituting the research. The study puts forward the use of technology, different modern teaching theories and practises, a deviation from normal teaching, innovative online teaching methods of English language skills, a difference of learning scenario, all intended to benefit students with different language levels and comprehensive capacities, and most significantly to balance and tone down lapses, if any, in online learning environment. The pre and post assessments of the participant students are statistically presented herewith which depicts the benefits as well as barriers of online language learning environment of college students in Tamil Nadu.
\end{abstract}

Keywords: Online Teaching Methodology, Comprehensive Capacities, Incubation, Competency,Connectedness.

\section{Introduction}

There are countless means to connect technology with education (Kenning, 2007). The platform of online classes is a part of online learning which includes web-based learning, online journals, educational movies, etc, all related to the technology in education. With a few keystrokes, students can search and get unlimited resources related to their studies. There are a number of pedagogic approaches that employ technology in education, like, project-based approach, web-based approach, online-based learning, etc. These approaches are either studentcentered, where the students have to do self-access learning; or teacher-centered, where the teacher plays the main role in delivering knowledge. In online-based learning approach for English language, the teacher acts as an instructor of the language subject and also guides the students to look for information on the internet. The teacher is not the sole source of knowledge since the role of instructional technology plays a big part.

Technologically enhanced means to encourage effective communication between the instructor and the students is a specific advantage of online English language teaching and learning among many other advantages. The researcher is committed to be a research initiative in providing quality English language programs relevant to the future career of the students, programmed with desired course materials and also to make their communication skill, which was a challenging one all these years, an easy - go process.

\section{Literature Review}

Kenneth Chapman, Vice President of Market Strategy at Distance2Learn stated, "The ability to participate in a safe environment is one of the hallmarks of online learning" (Onlineeducation.com, 2007). According to Raja Hussain (2004), "Ever since 2000, the number of colleges and universities offering online learning is increasing at a fastrate". Online learning is becoming a development in educational institutions as an alternative approach to the traditional classroom method. All course contents, communication and support provided to the students are online-based. It is a way to prevail over physical distance and bring people together by working out projects in a collaborative manner even when time difference is a restriction or even when faced with safety issues related to war or health, for example, the pandemic caused by COVID-19, etc. In short, knowledge and information can be accessed at any time and from anywhere in the world with technology advancement and online classes are a step forward in this regard. Karthikeyan et. al., (2019) Today tteachers engaging Gen ' $Z$ ' should implement innovative practices that uphold the tempo of their classroom teaching and learning process. Failing to update 
and maintain the rhythm, they are branded as inefficient teachers in spite of comprehensive subject knowledge and other subject skills.

Online teaching and learning is very suitable for self-access learning. Moreover, communication in webbased instructional design encourages users to use English because web designers also use English as the medium to deliver their content. As Garrison and Anderson (2003) rationalised, "A good example of a communication tool is in the form of discussion board that employs textual and graphic channels which leads to the practice of language and towards the end, the students will be able to learn the language naturally".

Learning English as a Second Language (ESL) has always been a challenging task especially for students for whom the language is new. Low proficiency students specially are less motivated to learn the language. This is aggravated by the lack of interesting and interactive learning environment (Lightbown \& Spada, 1999). The development of technology has enabled the setting up of a special environment which influences the language learning environment. It is hoped that the interaction between students and the technology may minimise feelings of anxiety and insecurity towards learning the language. Fennel (2001) stated that "If English is to be seen as a 'killer' language, communication technology must be interpreted as one of its major weapons". Past researches (e.g. Larsen-Freeman and Long (1991) have shown that online instruction of second language learning has possible positive effects on Second Language Acquisition (SLA) processes. This study will investigate the ideal environment and specific activities to examine the most vital positive effects in the usage of technology through online classes in language learning which can help students to acquire English as their second language better rather than depending on traditional language classroom alone.

\section{Study Analysis}

The proposed study analysis reveals a host of specific advantages that were incurred during the course of the research. As per the study, online language learning platform proves to be an imperative portal for college students in Tamil Nadu to develop and practice their language skill to a great extent. Few of the benefits detected and examined in the course of the study are listed below:

1. One of the primary benefits enjoyed and expressed by the student participants in their online language teaching is the flexibility of their scheduling aspect. The participant students were given the liberty to select their online English language course as per their comfort and available timing. The research study also experimented with asynchronous online sessions to provide maximum scheduling flexibility which proved to be of additional benefit to the students.

2. An almost perfect combination of stress free and total involvement of the students was observed in the online English language teaching carried out as part of the study at hand. Students shared about getting over their hesitations and fear since they are not graded or judged by their peers in online learning. It is observed that they also responded to the teacher on the dot without a care in the world. This gave a free and open learning environment which assisted all types of learners in the process.

3. The participant students experienced an incubation effect, which is a theory of creativity established by English psychologist Graham Wallas in 1926 that backs up the concept that incubating yourself positively affects memorisation by rejuvenating the brain. At the same time, as part of the study, the students were asked to share presentations during their online classes which paved the way for a break of the brain from the monotonous listening-teaching process.

4. The validity of the phrase "It's all in the mind" is observed to be true when it comes to learning a foreign language. The study detected that online English language teaching in general can serve as a paramount frame in linking the teacher, syllabus and mind of the students. Human psychology is a complex thing. The study spotted that online language teaching has a great impact on the learner's growth of mind set and grittiness (2 Gs) and also the confidence, control and connectedness of the learners (3 Cs).

The 2 Gs are both skills needed for language learning. Through these 2 Gs, the learners gather their level of proficiency, effort and learning strategies and investment of time for valuable purposes improves as well. As the learning competency of participant learners develops, they feel a sense of 'I can'. They become confident that they are personally able to manage and cope with learning a language. The learners also get empowered with a sense of control which let them benefit from being able to intentionally and proactively select and initiate the learning purposes. The connectedness between the language learner and the language trainer builds a personal connection to language as well. The confidence, control and connectedness (3Cs) developed by the learners in the course of their online classes is a boost in their language learning process. 
Equipped with these $2 \mathrm{Gs}$ and $3 \mathrm{Cs}$, the participant learners displayed a better understanding of why they are learning English language, the purpose of it and its value at present and in the future time.

1. The study reveals that learning through Google meet, Zoom meet, Google class room, etc, helps students hone the technical skill, the ability to use new software suites, perform in-depth research online in various formats such as discussion boards and teleconferencing. Almost all the participant students were not aware of these online portals before the study and they admitted the many advantages of learning online.

2. One of the biggest advantages witnessed during the course of this study was that the students need not move from their residence to attend the online classes. This is a time and money saving factor as well. Since they need not get physically ready to reach the place of learning, transport expenses gets totally nil in online learning process. They can attend the classes from anywhere in the world.

3. The participant students had the additional benefit of the total attention of the instructor who definitely prepares to make the content simple, clear and interesting to the students, thus offering more possibility for learners to become better talented and equipped.

4. Moreover, writing on the board during the classroom time consumes lot of time, but preparing PPT for online teaching prevents classroom time wastage for students because it will be pre-prepared by the tutor.

5. Students can record the lecture or the video displayed by the teacher for further verification and learning process.

\section{Method of the Study}

An experimental group of 22 college students were taken for the study. Students belong to different major subjects from different colleges. In the first day of interactive session, the students' level of competence in English language was assessed to get the baseline and a lesson plan for the online session training was drawn by the language trainer which was executed for a period of 30 days and the results are checked as per the exhibition of the learning outcomes among the students on completion of the study period.

\section{Proposed Study Model}

This study takes into consideration the psychological aspects of English language teaching by giving important attention to participant learners' recognition of concepts and ideas from different dimensions of behaviour and learning.

Based on the study's assertion, the researcher made a prior effort to know at least a little bit psychology of the learners before playing the role of instructor. The researcher took the responsibility to motivate the students in order to guide them according to their needs. An important aspect of the proposed model is to create a friendly and secure atmosphere for the students in the class to interact freely with the instructor. Respect is given to all learners, their individual mind and intelligence, their calibre, their level of language competency, all which were assessed in order to be sorted out to guide and coach them accordingly.

Another significant aspect of the proposed model is to psychologically create and develop the confidence level of the participant learners. This was carried out by encouraging and allowing the participant students to progress step by step in order to stimulate them to reach the mature frame of reference and thirst in the language. This aspect negates the practice of over imposing students with multiple content and tasks at the same time.

The proposed model is to ease the burden of psychological fears connected to learning since it is witnessed that students generally enter the online class with fear, stress and nervousness to express their inability. For many of the participant learners, the online mode of learning the English language will be a new development. Therefore, their apprehensions with online learning are anticipated to be minimised and played down with the proposed model.

In this connection, the study started with level based vocabulary enhancement sessions before delving into the other English language skills since vocabulary is an indispensable part of the English language learning process and a primary language skill that should be mastered by children before they acquire LSRW skills. 


\section{Specific Activities and Focus for the Study}

Table 1.1. Displays a Clear Cut View of the Activities and Assignments Given and the Positive Consequences among the Student Community the Basis of the Study Conducted

\begin{tabular}{|c|c|c|}
\hline S.no & Activities and Assignments & Result \\
\hline 1. & $\begin{array}{l}\text { Students were asked to frame sentences from } \\
\text { the lesson taught. Eg. Situational conversation. }\end{array}$ & $\begin{array}{l}\text { Their writing skill developed as they take initiation to } \\
\text { create new conversation. }\end{array}$ \\
\hline 2. & $\begin{array}{l}\text { Debates were conducted in the online class. On } \\
\text { the basis of the given topic, students were asked } \\
\text { to talk about their own opinion. }\end{array}$ & $\begin{array}{l}\text { This enhanced their speaking skill and helped students } \\
\text { develop their real potentiality in language } \\
\text { competency. }\end{array}$ \\
\hline 3. & $\begin{array}{l}\text { their } \\
\text { on daily basis. }\end{array}$ & $\begin{array}{l}\text { To prepare for the class presentation, they read and } \\
\text { referred quite a lot of materials. This certainly } \\
\text { improved their reading skill. }\end{array}$ \\
\hline 4. & $\begin{array}{l}\text { Tongu } \\
\text { given a }\end{array}$ & $\begin{array}{l}\text { s developed the concentration, thinking } \\
\text { unciation of students. }\end{array}$ \\
\hline 5. & $\begin{array}{l}\text { taught in class on a daily } \\
\text { were assigned to make use of } \\
\text { on their own. }\end{array}$ & $\begin{array}{l}\text { Learning more vocabularies in the course of the study } \\
\text { improved their standard of fluency in speaking and } \\
\text { writing too. }\end{array}$ \\
\hline 6. & $\begin{array}{l}\text { Videos related to communication were } \\
\text { displayed and students were asked to listen } \\
\text { carefully to reply to the questions posed by the } \\
\text { trainer. }\end{array}$ & $\begin{array}{l}\text { This raised students' listening ability and } \\
\text { comprehending capacity, which further served as a } \\
\text { mediator, headway and facilitator regarding language } \\
\text { enhancement. }\end{array}$ \\
\hline
\end{tabular}

\section{Data Analysis}

Table 1.2. Displays the Level of Percentage and Performance Indicators of the Learner Participants.

\begin{tabular}{ll}
\hline Percentage level. & Performance level. \\
\hline $0-30$ & Below average \\
$31-40$ & Average \\
$41-50$ & Satisfactory \\
$51-60$ & Good \\
$61-70$ & Very good \\
$71-80$ & Excellent \\
$81-90$ & Distinguished \\
$91-100$ & Highly distinguished. \\
\hline
\end{tabular}

As shown for this study, eight categories of performance indicator levels are allocated, out of which, the scoring category of 30 marks and below indicates a below average performance. A score of 31-40 marks shows an average performance, while a score of 41-50 marks indicates satisfactory performance. Performance percentage of 51-60 indicates a good performance level while a score between 61-70 marks shows very good performance. Excellent performance is indicated by a percentage level of 71-80 marks and a distinguished performance is indicated by $81-90$ percentage marks. A score of $91-100$ marks is an indicator of highly distinguished performance by the learner participants.

\section{Level of Performance before the Study}

Table 1.3. Percentage of Learning Indicators and Outcome Scored by the College Student Participants before the Online English Language Teaching Research Study

\begin{tabular}{llll}
\hline Percentage level & Performance level & Number of students & Percentage \\
\hline $0-30$ & Below average & 7 & 31.81 \\
$31-40$ & Average & 10 & 45.45 \\
$41-50$ & Satisfactory & 3 & 13.63 \\
$51-60$ & Good & 2 & 9.09 \\
$61-70$ & Very good & 0 & 0 \\
$71-80$ & Excellent & 0 & 0 \\
$81-90$ & Distinguished & 0 & 0 \\
$91-100$ & Highly distinguished & 0 & 0 \\
& & Total -22 & \\
\hline
\end{tabular}


Table 1.3 shows that $31.81 \%$ of the students were in below level and scored 30 marks and below in the test taken before the research study, while $45.45 \%$ were in average level with a score between $31-40$ marks. Only $13.63 \%$ of the participants were in satisfactory level before the commencement of the study with a score between 41-50 marks. Only 9.09\% of the participants were good with a score between 51-60 marks while no participants scored in the category of very good and excellent levels.

\section{Level of Performance after the Study}

Table 1.4. Percentage of Learning Indicators and Outcome Scored by the College Student Participants after the Online English Language Teaching Research Study

\begin{tabular}{llll}
\hline Percentage level & Performance level & Number of students & Percentage \\
\hline $0-30$ & Below average & 3 & 13.63 \\
$31-40$ & Average & 6 & 27.27 \\
$41-50$ & Satisfactory & 5 & 22.72 \\
$51-60$ & Good & 4 & 18.18 \\
$61-70$ & Very good & 3 & 13.63 \\
$71-80$ & Excellent & 1 & 4.54 \\
$81-90$ & Distinguished & 0 & 0 \\
$91-100$ & Highly distinguished & 0 & 0 \\
\hline
\end{tabular}

Total -22

Table 1.4 depicts that after the study period, the level of below average students decreased to13.63\% of the students, while the average level also decreased to $27.27 \%$. Meantime, the level of satisfactory performance increased to $22.72 \%$ of the participants, while the level of good performance also increased to $18.18 \%$ of the participants. While there was no very good and excellent level performance in the pre assessment, the post assessment registered a $13.63 \%$ of the participants in very good category and $4.54 \%$ in excellent category of performance level.

Table 1.5. Students' Performance Level Before and After the Conduct of Online Language Classes Regarding Listening, Speaking, Reading and Writing

\begin{tabular}{llllll}
\hline \multicolumn{1}{c}{ Particulars } & Listening & Speaking & Reading & Writing & Total \\
\hline Performance level before research study & 10.51 & 12.03 & 8.28 & 6.90 & 37.72 \\
Performance level after research study & 38.94 & 34.98 & 43.12 & 34.32 & 151.36 \\
\hline
\end{tabular}

Table 1.5 clearly depicts the marginal difference in the performance level of the participant students before and after the research study plan with regard to listening, speaking, reading and writing. A noticeable improvement in all the four language skills is observed during and after the completion of the study plan. Listening performance level increased from 10.51 to 38.94 , Speaking from 12.03 to 34.98 , Reading from 8.28 to 43.12 and Writing from 6.90 to 34.32. The skill of reading saw the best improvement in the post assessment followed by listening, writing and speaking. Reading and writing skills performance levels were in single digits before the research plan was implemented.

\section{Conclusion}

The research study ascertained a decreased anxiety in online classes, especially with regard to speaking in class in learning a second language by the participant students. The students produced better second language output when listening, speaking, reading and writing in the provided online learning environment compared to the output shown before the commencement of the study.

The study reveals that if students are provided an open and anxiety free environment to write, they take the required initiative to create their own output in writing which will develop their writing skill in the process. Further, the study shows that giving opportunities for students to share their views or to debate on topics of their choice will register improvement in their speaking skill which is an advantage in the process of acquiring language competency. Situational conversations help students to improve both their speaking and writing skills as they are free of nervousness and in a normal situation. At the same time, designated class presentations will push students to read and refer more than usual which will register an uptick in their reading skill. Part of language online study being fun activities, recitations and games like tongue twisters, the attention, assessment and pronunciation skills of the language learners will improve as shown by the study. The study proposed the learning of a wider range of vocabularies and recorded an improvement in the standard of fluency in all the skills of the language. The better prospects of audio visuals in online classes assist learners to improve their listening 
skills in order to be prepared for any discussions that may follow the viewing and listening time. It also supports the comprehending ability of learners to develop their language. All in all, it is observed that the online interactions among the student participants enhanced better collaborative and peer learning in the second language learning.

This online English language research study for college students enhancedthe overall English language proficiency in the aspects of listening, speaking, reading and writing. It developed the academic literacy of the all the participating college students, and will certainly assist all major students of English language in their further studies and research too. It will also pave the way to apply the requisite communication skills and strategies to their future careers. The programme will also let them engage in their self- directed English language learning and allow students to walk confidently with pride in all aspects of their life. They are certain to be responsible and fly out in colours as ethical English users.

In this era of modernisation and the current call for social distancing, the study concludes that language learners in colleges have much to gain from online platform learning with fun and interactive activities as well as a secure environment if teachers only dare to diversify their methodology of instruction by implementing the wonders of technology to make learning take place.

\section{References}

1. Anderson, T. (eds.), (2008). The Theory and Practice of Online Learning. Athabasca University Canada: AGMV Marquis, 459.

2. http://www.scribd.com/doc/15452301/Theory-and-Practice-of-Online-Learning.

3. Bertin, J.C., \& Narcy-Combes, J.P. (2007). Monitoring the learner-Who, why and what for?. Computer Assisted Language Learning, 20(5), 443-457.

4. Bruner, J. (1986). Actual Minds, Possible Worlds. Cambridge, MA: Harvard University Press.

5. Butler-Pascoe, M.E., \& Wiburg, K.M. (2003). Technology and Teaching English Language Learners. USA: Pearson Education, Inc.

6. Cooper, P.A. (1993). Paradigm Shifts in Designing Instruction: From Behaviorism to Cognitivism to Constructivism. Educational Technology, 33(5), 12-19.

7. Drever, E. (1990). Using Questionnaires in Small-Scale Research. Scotland: SCRE Publication.

8. Fennell, B.A. (2001). A History of English - a Sociolinguistic Approach. Oxford: Blackwell, 267.

9. Garrison, D.R., \& Anderson, T. (2003). E-Learning in the 21st century: A framework for research and practice. London: Routledge / Falmer. 1st Edition, 184. https://doi.org/10.4324/9780203166093

10. John Vijayakumar, I.S., \& Karthikeyan, J. (2019). Technology-Enabled Digital Language Learning Using a Flipped Innovation Model. In: Satapathy S., Bhateja V., Somanah R., Yang XS., Senkerik R. (eds) Information Systems Design and Intelligent Applications. Advances in Intelligent Systems and Computing, Springer, Singapore, 862.

11. Karthikeyan J., Christopher Rajasekaran W., \& Unyapho P. (2019). Analysis of Diverse Open Source Digital Tools and Learning Management System Users in Academics. In: Satapathy S., Bhateja V., Somanah R., Yang XS., Senkerik R. (eds) Information Systems Design and Intelligent Applications. Advances in Intelligent Systems and Computing, Springer, Singapore, 862.

12. Kenning, M. (2007). ICT and Language Learning from Print to the Mobile Phone. New York: Palgrave Macmillan.

13. Lai, C. (1994). Communication Failure in the Language Classroom: An Exploration of Causes. RELC Journal, 25(1), 99-129.

14. Larsen-Freeman, D., \& Long, M.H. (1991). An Introduction to Second Language Acquisition Research. London: Longman, 320-321.

15. Lightbown, P., \& Spada, N. (1999). How Languages are Learned. New York: Oxford University Press. Second Edition.

16. OnlineEducation.com, Instructional Methods for Online Learning,

17. https://www.onlineeducation.com/guide/instructional-methods

18. Hussain, R.M.R. (2004). E-learning in higher education institutions in Malaysia. E-mento, 5(7), 72-75. 